\title{
Fungia fungites (Linnaeus, 1758) (Scleractinia, Fungiidae) is a species complex that conceals large phenotypic variation and a previously unrecognized genus
}

\author{
Yutaro Oku \\ Interdisciplinary Graduate School of Agriculture and Engineering, University of Miyazaki, \\ 1-1 Gakuen-kibanadai-nishi, Miyazaki, Miyazaki, 889-2192, Japan
}

Kenji Iwao

Akajima Marine Science Laboratory, 179 Aka, Zamami, Okinawa 901-3311, Japan

Present address: Graduate School of Agriculture, Ehime University, 3-5-7 Tarumi,

Matsuyama, Ehime, 790-8566, Japan

Bert W. Hoeksema

Naturalis Biodiversity Center, PO Box 9517, 2300 RA Leiden, The Netherlands

Groningen Institute for Evolutionary Life Sciences, University of Groningen, Groningen,

The Netherlands

\section{Naoko Dewa}

Kagoshima City Aquarium, 3-1 Honkoshin-machi, Kagoshima, Kagoshima 892-0814, Japan

Hiroyuki Tachikawa

Coastal Branch of Natural History Museum and Institute, Chiba, 123 Yoshio, Katsuura, Chiba 299-5242, Japan

\section{Tatsuki Koido}

Interdisciplinary Graduate School of Agriculture and Engineering, University of Miyazaki, 1-1 Gakuen-kibanadai-nishi, Miyazaki, Miyazaki, 889-2192, Japan

Kuroshio Biological Research Foundation, 56o Nishidomari, Otsuki, Hata, Kochi 788-0333, Japan

\section{Hironobu Fukami}

Department of Marine Biology and Environmental Sciences, Faculty of Agriculture, University of Miyazaki, 1-1 Gakuen-kibanadai-nishi, Miyazaki, Miyazaki, 889-2192, Japan hirofukami@cc.miyazaki-u.ac.jp

\footnotetext{
Abstract

Recent molecular phylogenetic analyses of scleractinian corals have resulted in the discovery of cryptic lineages. To understand species diversity in corals, these lineages need to be taxonomically defined. In 
the present study, we report the discovery of a distinct lineage obscured by the traditional morphological variation of Fungia fungites. This taxon exists as two distinct morphs: attached and unattached. Molecular phylogenetic analyses using mitochondrial COI and nuclear ITS markers as well as morphological comparisons were performed to clarify their phylogenetic relationships and taxonomic positions. Molecular data revealed that $F$. fungites consists of two genetically distinct clades (A and B). Clade A is sister to a lineage including Danafungia scruposa and Halomitra pileus, while clade B formed an independent lineage genetically distant from these three species. The two morphs were also found to be included in both clades, although the attached morph was predominantly found in clade A. Morphologically, both clades were statistically different in density of septal dentation, septal number, and septal teeth shape. These results indicate that $F$. fungites as presently recognized is actually a species complex including at least two species. After checking type specimens, we conclude that specimens in clade A represent true $F$. fungites with two morphs (unattached and attached) and that all of those in clade B represent an unknown species and genus comprising an unattached morph with only one exception. These findings suggest that more unrecognized taxa with hitherto unnoticed morphological differences can be present among scleractinian corals.

\section{Keywords}

COI - ITS - mushroom coral - morphological plasticity - phylogeny - taxonomy

\section{Introduction}

Over the last two decades, molecular phylogenetic and subsequent morphological analyses have been applied to scleractinian corals (Cnidaria: Anthozoa) to infer phylogenetic relationships and to revise their taxonomy (Fukami et al., 2008; Budd et al., 2012; Huang et al., 2014a, b; Kitahara et al., 2016). For example, within the family Lobophylliidae Dai \& Horng, 2009, molecular data showed that various genera were polyphyletic (Arrigoni et al., 2014a, b, 2015), conflicting with traditional morphology-based taxonomy. As a result of the search for morphological characters that reflect molecular phylogeny, several species and genera have been newly described taxonomically or resurrected (Arrigoni et al., 2015, 2016a, b, 2019; Huang et al., 2016; Benzoni et al., 2018). In the family Fungiidae Dana, 1846, the taxonomy of 26 species were revised based primarily on molecular phylogenetic data (Gittenberger et al., 2011).
Additionally, two species, Cycloseris explanulata (van der Horst, 1922) and C. wellsi (Veron \& Pichon, 1980), were transferred from other families (Psammocoridae Chevalier \& Beauvais, 1987 and Coscinaraeidae Benzoni, Arrigoni, Stefani \& Stolarski, 2012, respectively) to be included in the Fungiidae (Benzoni et al., 2012). Similar taxonomic revisions have been reported in other families, such as Acroporidae Verrill, 1902 (Wallace et al., 2007; Richards et al., 2019), Siderastreidae Vaughan \& Wells, 1943 (Benzoni et al., 2010), Poritidae Gray, 1840 (Kitano et al., 2014), and Euphylliidae Alloiteau, $195^{2}$ (Luzon et al., 2017). Furthermore, some genera (e.g., Blastomussa, Nemenzophyllia, Pachyseris, Plerogyra) had to be removed from their families and were temporarily placed in Scleractinia incertae sedis (Benzoni et al., 2014; Terraneo et al., 2014; Hoeksema \& Cairns, 2019a). In many of these cases, new genera and species were described when their phylogenetic relationships were clearly different by using mitochondrial markers such as 
cytochrome oxidase I (COI), cytochrome b, and ${ }_{16 S}$ rRNA. Of these, COI, which is known to have relatively little intraspecific variation (Huang et al., 2008), is commonly used in corals and shown to be especially effective for estimating phylogenetic relationships at the family and genus levels.

Molecular phylogenetic analyses have also contributed to the discovery of hidden coral species (Arrigoni et al., 2016a, b, 2019), resulting from molecular analyses using nuclear markers such as internal transcribed spacers (ITS) of ribosomal RNA gene and the intron region of the $ß$-tubulin gene. These were described as new species after detailed morphological analyses (Arrigoni et al., 2016a, b, 2017, 2019; Baird et al., 2017). In addition, extensive phylogeographic research with microsatellite markers also contributed to the discovery of cryptic lineages. For example, such studies revealed that many cryptic species may exist among Indo-Pacific Acropora spp. (Richards et al., 2016). Especially in Acropora hyacinthus (Dana, 1846), three to five cryptic genotypes have been reported from several localities in the Indo-Pacific (Ladner \& Palumbi, 2012; Suzuki et al., 2016; Nakabayashi et al., 2019). Similarly, many cryptic genotypes have been reported among other coral species, especially widespread taxa like Pocillopora damicornis (Linnaeus, 1758) (e.g., SchmidtRoach et al., 2013), Stylophora pistillata Esper, 1797 (e.g., Stefani et al., 2011; Keshavmurthy et al., 2013), and Seriatopora hystrix Dana, 1846 (e.g., Bongaerts et al., 2010; Warner et al., 2015).

Hence, integrated analyses combining molecular and morphological data enable coral specialists to infer taxonomic positions more precisely and to find hidden species or cryptic lineages among corals. However, it is difficult to find specific morphological characteristics of hidden species or cryptic lineages in order to separate them from closely related species. One reason for this is due to colony formation, a trait typical of many corals that leads to large morphological variation among individual corallites (the cup-like skeletal structures of polyps) within a colony, and also between colonies. Such morphological variation can be caused by different environmental factors (Todd, 2008; Chen et al., 2011) or differences in genotypes (Carlon \& Budd, 2002), eventually resulting in larger intraspecific variation. In order to solve this problem of detecting new morphological differences among closely related species, micromorphological analysis using scanning electron microscopy has been applied as aid in recent taxonomic revisions of corals (Gittenberger et al., 2011; Budd et al., 2012; Huang et al., 2014a, b; Arrigoni et al., 2014a, b, c, 2015, 2016a, b, 2019).

Fungia Lamarck, 1801, the type genus of the family Fungiidae, includes only one species, F. fungites, which is usually unattached (freeliving when full-grown) and common on shallow Indo-Pacific reefs. As with most other unattached fungiids (Hoeksema \& Gittenberger, 2010; Hoeksema \& Waheed, 2012; Hoeksema \& Benzoni, 2013; Hoeksema 2014), larvae of this species settle on a solid substratum, remain attached by a stalk at the juvenile (anthocaulus) stage (Hoeksema, 1989), and become unattached in the adult stage (anthocyathus) after detaching a disc with a diameter of less than $50 \mathrm{~mm}$ from the stalk (Goffredo \& Chadwick-Furman, 2003; Gilmour, 2004). However, a unique characteristic only in $F$. fungites, an attached morph (remaining attached with a disc of more than $50 \mathrm{~mm}$ in a diameter), has been reported in Thailand and Japan. In Thailand, Hoeksema \& Yeemin (2011) reported that it remained attached with a disc up to 125 mm in diameter. In Japan, Nishihira \& Veron (1995) also found the attached morph, but they considered it a different species, "Fungia sp. (Sessile)". 
In order to uncover whether the two morphs (the attached and unattached morphs) of $F$. fungites are separate species, and to determine whether F. fungites comprise cryptic lineages, we collected specimens of both morphs in Japan. We investigated their molecular phylogenetic positions, and studied micromorphological skeletal characters. While we found that the two morphs reflect intraspecific variation of $F$. fungites, we also discovered one likely new species, which is morphologically closely related to but genetically distant from the true $F$. fungites.

\section{Material and methods}

\section{Sampling and species identification}

Two morphs (attached and unattached morphs) of $F$. fungites were collected by SCUBA diving on reefs at six islands of the Nansei Island group, southern Japan (fig. 1). Depth of each specimen was also recorded. In Aka Is. and Iriomote Is., corals were collected with the permissions of the governor of Okinawa Prefecture (permission numbers 24-6o, 31-53). After sampling, a fragment $\left(<1 \mathrm{~cm}^{3}\right)$ of each specimen was preserved in CHAOS solution (4M guanidine thiocyanate, $0.1 \%$ $\mathrm{N}$-lauroyl sarcosine sodium, 10mM Tris-HCl pH 8, o.1M 2-mercaptoethanol; Fukami et al., 2004) for DNA analysis, and the remnant samples were bleached for morphological analysis. In addition, we also collected specimens of Danafungia scruposa (Klunzinger, 1879) and Halomitra pileus (Linnaeus, 1758), which are known to be closely related to $F$. fungites (Gittenberger et al., 2011; Oku et al., 2017), and Lobactis scutaria (Lamarck, 1801) as outgroup. All specimens were identified at species level,

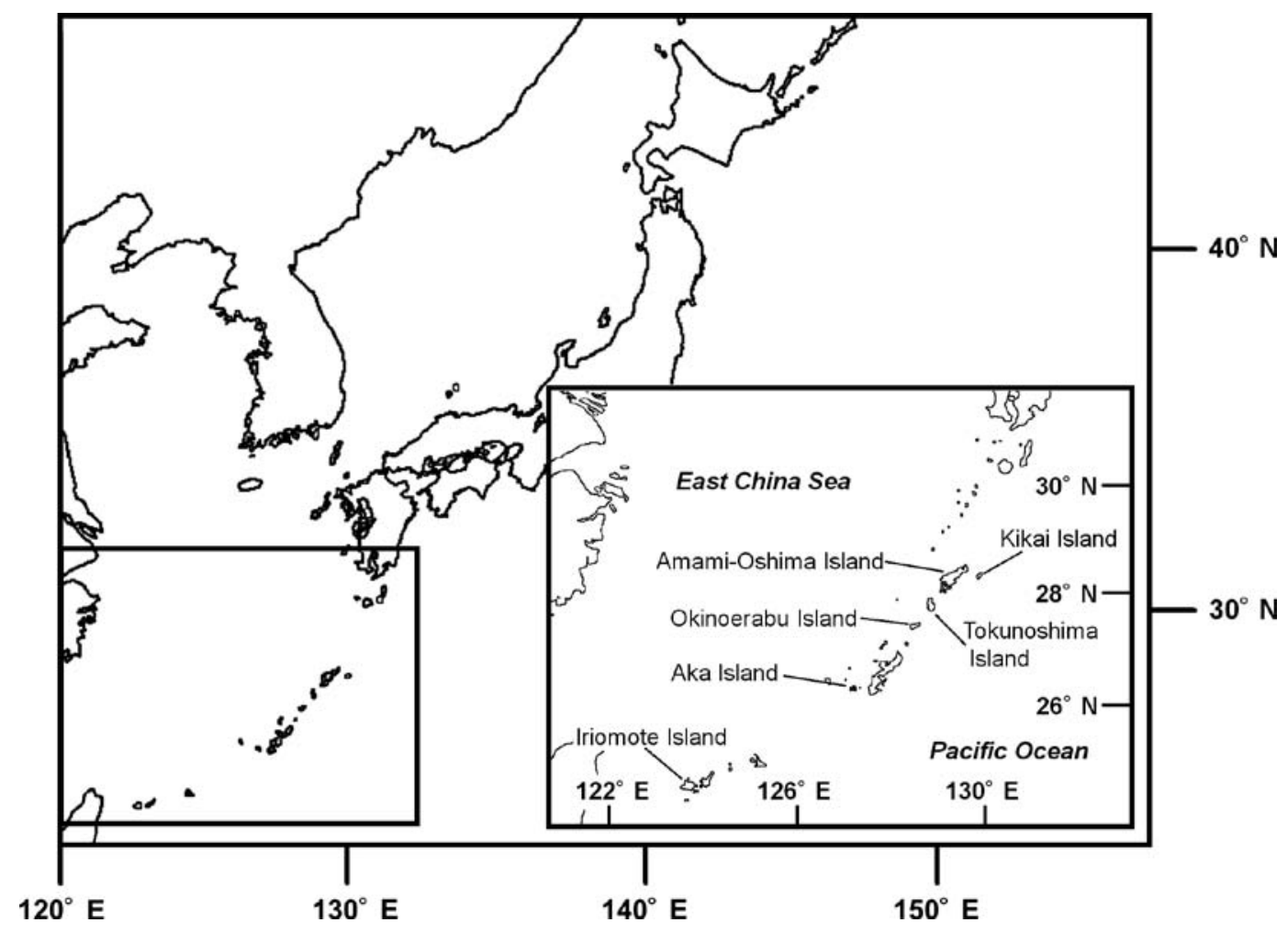

FIGURE 1 Map of the sampling sites. 
based on original descriptions and related references (e.g., Linnaeus, 1758; Lamarck, 1801; Klunzinger, 1879; Hoeksema, 1989). Voucher samples were deposited at the University of Miyazaki (MUFS, Miyazaki, Japan).

\section{Molecular phylogenetic analysis}

Total DNA from each specimen was extracted from tissue dissolved in CHAOS solution, using a conventional phenol/chloroform extraction method. The barcoding portion of the mitochondrial COI, and ITS of the nuclear ribosomal DNA (including partial 18S, ITS-1, 5.8S, ITS-2, and partial $28 \mathrm{~S}$ ) were amplified using polymerase chain reaction (PCR) with the primers COI mod F and R (Gittenberger et al., 2011) for COI, and primers $1 S$ and $2 S S$ (Wei et al., 2006) for ITS. PCR conditions described by Oku et al. (2017) were used in this study. The DNA sequences were determined by direct sequencing using ABI373o sequencers (Applied Biosystems, Alameda, California, USA). All the DNA sequences obtained in the present study were submitted to DNA Data Bank of Japan, DDBJ (accession Nos. LC484501LC484628). DNA sequences were aligned with Sequencher ver. 5.1 (Gene Codes, Ann Arbor, MI, USA). Phylogenetic trees were reconstructed using the neighbor-joining $(\mathrm{NJ})$ and maximum-likelihood (ML) methods. For the $\mathrm{NJ}$ and ML, we assumed a model of nucleotide evolution obtained using MEGA ver. 7.0 (Kumar et al., 2016). The most appropriate models of nucleotide evolution were the HasegawaKishino-Yano model for the COI marker, and Jukes-Cantor model with gamma distribution (G) for the ITS marker. MEGA was used to estimate the topologies for each marker and to conduct a bootstrap analysis (with 1000 replicates). For both COI and ITS trees, we used as outgroup L. scutaria, which is phylogenetically closest to our target species (Gittenberger et al., 2011; Oku et al., 2017). We also concatenated both markers and performed an analysis along with available DNA data to confirm the phylogenetic position of $F$. fungites within Fungiidae. These sequences were obtained from three previous studies (Fukami et al., 2008; Gittenberger et al., 2011; Oku et al., 2017), and accession numbers are included in supplementary fig. S1.

\section{Morphological analysis}

To investigate the morphological differences of two morphs in F. fungites, we first classed them into two growth stages - immature (juvenile) and mature (full-grown) - because corals in the immature stage usually exhibit atypical morphology (Baird and Babcock, 2000; Babcock et al., 2003). We defined the immature stage as having a diameter of less than $50 \mathrm{~mm}$, because $F$. fungites typically detaches itself from the substrate when reaching approximately this size (Goffredo \& ChadwickFurman, 2003; Gilmour, 2004). The mature stage for both morphs was defined as having a diameter of $50 \mathrm{~mm}$ or more. We examined corallum diameter, number of septa, and density of septal dentation and costal spines for all specimens (fig. 2) using a digital microscope (VHX-100o, Keyence). In addition to these morphological skeleton exanimations, we examined the micromorphological characters of septal teeth and septal side with scanning electron microscopy (SEM) using TM-100o (Hitachi High-Technologies Corp., Tokyo, Japan). To avoid measurement bias for density of septal dentation (teeth), we randomly selected five septa from all septa reaching around the mouth and counted the number of septal teeth within $1 \mathrm{~cm}$ of the middle part of each selected septum (fig. 2b). Similarly, to assess the density of costal spines, we randomly selected five out of all costae and counted the number of costal spines within 1 $\mathrm{cm}$ of the middle part of each selected costa (fig. 2b). For these characteristics, the mean values of specimens were calculated from five replicates. The Kruskal-Wallis test was used to test whether density of septal dentation Downloaded from Brill. Come4/26/2023 11:58:21AM 


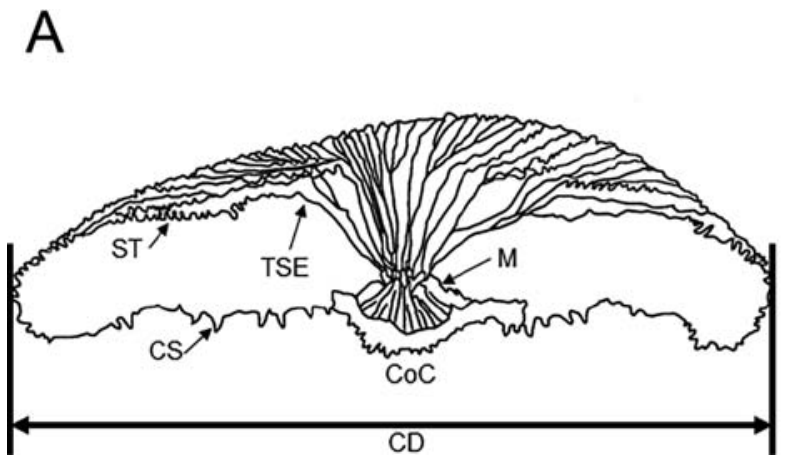

B

FIGURE 2 Schematic illustration of Fungia fungites. A. Cross section in F. fungites. B. Side view of septum. Abbreviations and symbols: CD, Corallum diameter; $\mathrm{CoC}$, Center of corallum; CS, Costal spine; $\mathrm{M}$, Mouth; ST, Septal tooth; TSE, Top of septal edge; a, density of septal dentation; b, density of costal spine.

and costal spines were significantly different between three groups (two morphs and immature specimens). Non-parametric pairwise analyses were done using the Steel-Dwass test. Finally, significant differences between two samples for morphological characteristics were tested using the Mann-Whitney $\mathrm{U}$ test. Statistical tests were performed using $\mathrm{R}$ ver. 3.5.3 (R Core Team, 2019).

\section{Results}

\section{Molecular analysis}

For COI analysis, DNA sequences of immature specimens (12 specimens), and two morphs (11 for attached, 31 for unattached) of $F$. fungites were obtained, in addition to those of D. scruposa (five specimens) and H. pileus (4) (table 1). We obtained 505 positions for COI in total, including 11 polymorphic and parsimony-informative sites, and no indel was observed. A COI phylogenetic tree showed that F. fungites formed two distinct clades (clades A and B) (fig. 3). Clade A included eight immature specimens, 18 unattached morphs, and 10 attached morphs, whereas clade B included four immature specimens, 13 unattached morphs, and only one attached morph. Each of D. scruposa and H. pileus formed an independent clade between clades $A$ and $B$, forming sister clades with clade A.

For ITS analysis, DNA sequences of 54 specimens (12 specimens for immature, 11 for attached, $3_{1}$ for unattached) of $F$. fungites were obtained, in addition to those of five specimens of D. scruposa and two specimens of H. pileus (table 1). We obtained 937 positions, including 40 polymorphic sites with 24 parsimony-informative sites, and all indels were deleted from the analysis. An ITS phylogenetic tree showed a topology similar to that of the COI tree, in which F. fungites was divided into genetically distant clades (fig. 4). Overall, bootstrap values of the ITS tree were lower than those of the COI tree. Danafungia scruposa and $H$. pileus were phylogenetically positioned between two clades $\mathrm{A}$ and $\mathrm{B}$, forming sister clades with clade $\mathrm{A}$, as in the $\mathrm{COI}$ tree.

For concatenated COI-ITS analysis, we obtained 1,087 positions, including 178 polymorphic sites with 105 parsimony-informative sites, and all indels were deleted from the analysis. In this tree, $F$. fungites was also divided into two distant clades. The DNA sequence of one sample of $F$. fungites used in Gittenberger et al. (2011) was in clade B (supplementary fig. S1). 
TABLE 1 List of specimens used in this study. Each with corresponding species, specimen name, sampling name, locality, morph (only for Fungia fungites and Fungiidae sp.), DDBJ accession numbers.

Abbreviations: MUFS, University of Miyazaki, Fisheries Science; NA, Not Analysis; NR, Not Record

\begin{tabular}{|c|c|c|c|c|c|c|c|c|}
\hline & $\begin{array}{l}\text { Specimen } \\
\text { No. }\end{array}$ & $\begin{array}{l}\text { Sample } \\
\text { No. }\end{array}$ & Locality & $\begin{array}{l}\text { Depth } \\
(\mathrm{m})\end{array}$ & $\begin{array}{l}\text { Diameter } \\
(\mathrm{mm})\end{array}$ & $\begin{array}{l}\text { Morpho- } \\
\text { type }\end{array}$ & COI & ITS \\
\hline Clade A & MUFS C 300 & $\mathrm{AKF}_{2}$ & Aka Is. & $<5$ & 46.2 & Immature & LC484501 & LC 484566 \\
\hline (Fungia & MUFS C 301 & $\mathrm{AKF}_{43}$ & Aka Is. & $<5$ & 42.9 & Immature & LC484502 & $\mathrm{LC}_{4} 84567$ \\
\hline \multirow[t]{34}{*}{ fungites) } & MUFS C302 & DTKN1 & Tokunoshima Is. & $<5$ & 29.1 & Immature & LC484503 & LC4 484568 \\
\hline & MUFS C 303 & $\mathrm{DTKN}_{2}$ & Tokunoshima Is. & $<5$ & 33.2 & Immature & LC484504 & LC484569 \\
\hline & MUFS C304 & $\mathrm{DTKN}_{3}$ & Tokunoshima Is. & $<5$ & 29.4 & Immature & $\mathrm{LC}_{4} 845^{\circ} 5$ & $\mathrm{LC}_{4} 84570$ \\
\hline & MUFS C 305 & $\mathrm{DTKN}_{4}$ & Tokunoshima Is. & $<5$ & 40.1 & Immature & LC4845o6 & LC484571 \\
\hline & MUFS $C_{3} 06$ & $\mathrm{~F}_{7}$ & Okinoerabu Is. & $<1$ & 39.8 & Immature & LC484507 & LC484572 \\
\hline & MUFS C307 & IR391 & Iriomote Is. & $<5$ & $45 \cdot 4$ & Immature & LC484508 & $\mathrm{LC}_{4} 84573$ \\
\hline & MUFS $C_{308}$ & AKFn1 & Aka Is. & $<5$ & 55.0 & Attached & LC484509 & LC484574 \\
\hline & MUFS C309 & $\mathrm{AKF}_{27}$ & Aka Is. & $<5$ & 74.7 & Attached & LC484510 & LC484575 \\
\hline & MUFS C 310 & $\mathrm{AKF}_{3} 6$ & Aka Is. & $<5$ & $5^{6.1}$ & Attached & LC484511 & $\mathrm{LC}_{4} 84576$ \\
\hline & MUFS C 311 & $\mathrm{AKF}_{47}$ & Aka Is. & $<5$ & 59.9 & Attached & LC484512 & LC484577 \\
\hline & MUFS C 312 & DKKI & Kikai Is. & $<5$ & $95 \cdot 3$ & Attached & LC484513 & LC 484578 \\
\hline & MUFS C 313 & DKKI2 & Kikai Is. & $<5$ & 72.7 & Attached & $\mathrm{LC}_{4} 84514$ & LC484579 \\
\hline & MUFS C314 & $\mathrm{DKKI}_{3}$ & Kikai Is. & $<5$ & $5^{6.8}$ & Attached & $\mathrm{LC}_{4} 84515$ & $\mathrm{LC}_{4} 845^{80}$ \\
\hline & MUFS C 315 & F8 & Okinoerabu Is. & $<1$ & 67.4 & Attached & $\mathrm{LC}_{4} 84516$ & $\mathrm{LC}_{4} 84581$ \\
\hline & MUFS $C_{316}$ & $\mathrm{~F} 17$ & Okinoerabu Is. & $<1$ & 62.6 & Attached & LC484517 & LC4 $445^{82}$ \\
\hline & MUFS C 317 & $\mathrm{~F} 18$ & Okinoerabu Is. & $<1$ & $51 \cdot 3$ & Attached & LC484518 & LC $4845^{8} 3$ \\
\hline & MUFS $C_{318}$ & $\mathrm{AKF}_{59}$ & Aka Is. & $<5$ & 66.4 & Unattached & LC484519 & LC 484584 \\
\hline & MUFS C 278 & $\mathrm{AOU}_{3} 8_{3}$ & Amami-Oshima Is. & $10-11$ & 64.2 & Unattached & LC $4845^{20}$ & $\mathrm{LC}_{4} 845^{85}$ \\
\hline & MUFS C 319 & F9 & Okinoerabu Is. & $<1$ & 66.6 & Unattached & $\mathrm{LC}_{4} 845^{21}$ & $\mathrm{LC}_{4} 84586$ \\
\hline & MUFS C 320 & F16 & Okinoerabu Is. & $<1$ & 74.9 & Unattached & LC $4845^{22}$ & LC $4845^{8} 7$ \\
\hline & MUFS C 321 & IR273 & Iriomote Is. & NR & 70.9 & Unattached & $\mathrm{LC}_{4} 845^{23}$ & $\mathrm{LC}_{4} 845^{88}$ \\
\hline & MUFS C 322 & IR 278 & Iriomote Is. & NR & 61.5 & Unattached & $\mathrm{LC}_{4} 845^{24}$ & LC 484589 \\
\hline & MUFS $C_{323}$ & $\mathrm{IR}_{28} 8$ & Iriomote Is. & 10.0 & 58.9 & Unattached & LC484525 & LC48459o \\
\hline & MUFS C 324 & IR286 & Iriomote Is. & 10.9 & 87.7 & Unattached & LC4 $445^{26}$ & $\mathrm{LC}_{4} 84591$ \\
\hline & MUFS $C_{325}$ & IR291 & Iriomote Is. & $10-11$ & 68.2 & Unattached & LC 484527 & LC 484592 \\
\hline & MUFS $C_{326}$ & IR292 & Iriomote Is. & $10-11$ & $115 \cdot 5$ & Unattached & $\mathrm{LC}_{4} 845^{28}$ & LC484593 \\
\hline & MUFS C327 & IR294 & Iriomote Is. & $10-11$ & 99.6 & Unattached & $\mathrm{LC}_{4} 845^{29}$ & LC484594 \\
\hline & MUFS $C_{328}$ & $\mathrm{IR}_{300}$ & Iriomote Is. & 11.6 & 66.6 & Unattached & $\mathrm{LC}_{4} 84530$ & LC484595 \\
\hline & MUFS C 329 & $\mathrm{IR}_{320}$ & Iriomote Is. & $7-8$ & 62.9 & Unattached & $\mathrm{LC}_{4} 84531$ & $\mathrm{LC}_{4} 84596$ \\
\hline & MUFS C 330 & $\mathrm{IR}_{327}$ & Iriomote Is. & 9.8 & 92.9 & Unattached & $\mathrm{LC}_{4} 8453^{2}$ & LC484597 \\
\hline & MUFS C 331 & IR330 & Iriomote Is. & $<5$ & 68.2 & Unattached & $\mathrm{LC}_{4} 84533$ & $\mathrm{LC}_{4} 84598$ \\
\hline & MUFS C 332 & $\mathrm{IR}_{3} 85$ & Iriomote Is. & 6.8 & 82.3 & Unattached & LC484534 & LC484599 \\
\hline & MUFS C333 & $\mathrm{IR}_{3} 88$ & Iriomote Is. & 10.6 & 101.3 & Unattached & LC484535 & LC 484600 \\
\hline & MUFS C 334 & $\mathrm{IR}_{394}$ & Iriomote Is. & $5 \cdot 7$ & 104.1 & Unattached & $\mathrm{LC}_{4} 84536$ & $\mathrm{LC}_{4} 84601$ \\
\hline
\end{tabular}


TABLE 1 List of specimens used in this study. Each with corresponding species, specimen name (cont.)

\begin{tabular}{|c|c|c|c|c|c|c|c|c|}
\hline & $\begin{array}{l}\text { Specimen } \\
\text { No. }\end{array}$ & $\begin{array}{l}\text { Sample } \\
\text { No. }\end{array}$ & Locality & $\begin{array}{l}\text { Depth } \\
(\mathrm{m})\end{array}$ & $\begin{array}{l}\text { Diameter } \\
(\mathrm{mm})\end{array}$ & $\begin{array}{l}\text { Morpho- } \\
\text { type }\end{array}$ & COI & ITS \\
\hline Clade B & MUFS C335 & AKF67 & Aka Is. & $<5$ & 47.8 & Immature & $\mathrm{LC} 484537$ & $\mathrm{LC} 484602$ \\
\hline (Fungiidae & MUFS C 336 & AKF91 & Aka Is. & $7-8$ & 37.2 & Immature & $\mathrm{LC}_{4} 8453^{8}$ & $\mathrm{LC}_{4} 84603$ \\
\hline \multirow[t]{16}{*}{ sp.) } & MUFS C337 & AOU177 & Amami-Oshima Is. & $5^{-10}$ & $49 \cdot 4$ & Immature & LC484539 & $\mathrm{LC}_{4} 84604$ \\
\hline & MUFS C166 & $\mathrm{AOU}_{2} 63$ & Amami-Oshima Is. & 12.5 & 46.2 & Immature & LC484540 & $\mathrm{LC}_{4} 84605$ \\
\hline & MUFS C188 & AOU292 & Amami-Oshima Is. & $<5$ & 53.8 & Attached & $\mathrm{LC} 484541$ & $\mathrm{LC} 484606$ \\
\hline & MUFS C 338 & $\mathrm{AKF}_{71}$ & Aka Is. & $7-8$ & 126.7 & Unattached & $\mathrm{LC}_{4} 84542$ & $\mathrm{LC}_{4} 84607$ \\
\hline & MUFS C 339 & $\mathrm{AKF}_{72}$ & Aka Is. & $7-8$ & 81.7 & Unattached & $\mathrm{LC}_{4} 84543$ & $\mathrm{LC}_{4} 84608$ \\
\hline & MUFS C 340 & $\mathrm{AKF}_{73}$ & Aka Is. & $7-8$ & 101.5 & Unattached & $\mathrm{LC}_{4} 84544$ & $\mathrm{LC}_{4} 84609$ \\
\hline & MUFS C 341 & $\mathrm{AKF}_{74}$ & Aka Is. & $7-8$ & $95 \cdot 9$ & Unattached & $\mathrm{LC}_{4} 84545$ & $\mathrm{LC}_{4} 84610$ \\
\hline & MUFS C 342 & $\mathrm{AKF}_{79}$ & Aka Is. & $7-8$ & 120.9 & Unattached & LC484546 & $\mathrm{LC}_{484611}$ \\
\hline & MUFS C 343 & AKF88 & Aka Is. & $7-8$ & 70.2 & Unattached & $\mathrm{LC} 484547$ & $\mathrm{LC}_{4} 84612$ \\
\hline & MUFS C344 & AOU121 & Amami-Oshima Is. & 6.2 & 121.4 & Unattached & LC484548 & $\mathrm{LC}_{4} 84613$ \\
\hline & MUFS C 345 & AOU186 & Amami-Oshima Is. & $5^{-10}$ & 66.2 & Unattached & LC484549 & $\mathrm{LC}_{4} 84614$ \\
\hline & MUFS C 346 & AOU205 & Amami-Oshima Is. & $5^{-10}$ & 127.0 & Unattached & $\mathrm{LC}_{4} 8455^{\circ}$ & $\mathrm{LC}_{4} 84615$ \\
\hline & MUFS C347 & AOU217 & Amami-Oshima Is. & $5^{-10}$ & 120.9 & Unattached & $\mathrm{LC}_{484551}$ & $\mathrm{LC}_{4} 84616$ \\
\hline & MUFS C228 & $\mathrm{AOU}_{336}$ & Amami-Oshima Is. & $<5$ & 87.6 & Unattached & $\mathrm{LC} 48455^{2}$ & $\mathrm{LC} 484617$ \\
\hline & MUFS C 348 & IR402 & Iriomote Is. & 14.0 & 64.5 & Unattached & $\mathrm{LC}_{4} 84553$ & $\mathrm{LC}_{4} 84618$ \\
\hline & MUFS C349 & IR407 & Iriomote Is. & 11.8 & $77 \cdot 3$ & Unattached & LC484554 & $\mathrm{LC}_{484619}$ \\
\hline Danafungia & MUFS C $35^{\circ}$ & AOU108 & Amami-Oshima Is. & & & & $\mathrm{LC}_{4} 84555$ & $\mathrm{LC}_{4} 84620$ \\
\hline \multirow[t]{4}{*}{ scruposa } & MUFS C $35^{1}$ & AOU109 & Amami-Oshima Is. & & & & $\mathrm{LC}_{4} 8455^{6}$ & $\mathrm{LC}_{4} 84621$ \\
\hline & MUFS C $35^{2}$ & AOU118 & Amami-Oshima Is. & & & & $\mathrm{LC} 484557$ & $\mathrm{LC} 484622$ \\
\hline & MUFS C 353 & AM664 & Amami-Oshima Is. & & & & $\mathrm{LC}_{4} 8455^{8}$ & $\mathrm{LC} 484623$ \\
\hline & MUFS C354 & AM665 & Amami-Oshima Is. & & & & LC484559 & $\mathrm{LC}_{4} 84624$ \\
\hline \multirow{4}{*}{$\begin{array}{l}\text { Halomitra } \\
\text { pileus }\end{array}$} & MUFS C144 & IR191 & Iriomote Is. & & & & LC191477 & LC191512 \\
\hline & MUFS C 355 & IR266 & Iriomote Is. & & & & $\mathrm{LC}_{4} 845^{60}$ & NA \\
\hline & MUFS C 356 & $\mathrm{IR} 268$ & Iriomote Is. & & & & $\mathrm{LC}_{4} 845^{61}$ & NA \\
\hline & MUFS C 357 & IR275 & Iriomote Is. & & & & $\mathrm{LC}_{4} 84562$ & LC484625 \\
\hline \multirow{3}{*}{$\begin{array}{l}\text { Lobactis } \\
\text { scutaria }\end{array}$} & MUFS C $35^{8}$ & $\mathrm{AKF} 16$ & Aka Is. & & & & $\mathrm{LC}_{4} 845^{6} 3$ & $\mathrm{LC}_{4} 84626$ \\
\hline & MUFS C 359 & AKF66 & Aka Is. & & & & $\mathrm{LC}_{4} 84564$ & $\mathrm{LC}_{484627}$ \\
\hline & MUFS C 360 & $\mathrm{AKF}_{77}$ & Aka Is. & & & & $\mathrm{LC}_{4} 845^{65}$ & $\mathrm{LC}_{4} 84628$ \\
\hline
\end{tabular}

\section{Morphological comparison}

We focused on the comparison between clades, and compared morphological data of specimens between clades A and B, because the two morphs were included in both clades. Morphological data of the two morphs and immature specimens from each clade are summarized in table 2. Three morphological differences were observed in the specimens (including immature and two morphs) between clades A and B. The first was density of septal dentations, which appeared to be the most useful characteristic for distinguishing between clades. It was significantly different (Mann-Whitney U test: $U=12.5, N=54$, $P<0.0001)$ between all specimens of clades A (8-22 teeth per $\mathrm{cm})$ and those of clade $B(12-33$ teeth per $\mathrm{cm}$ ) (fig. 5 , table 2 ), whereas density 


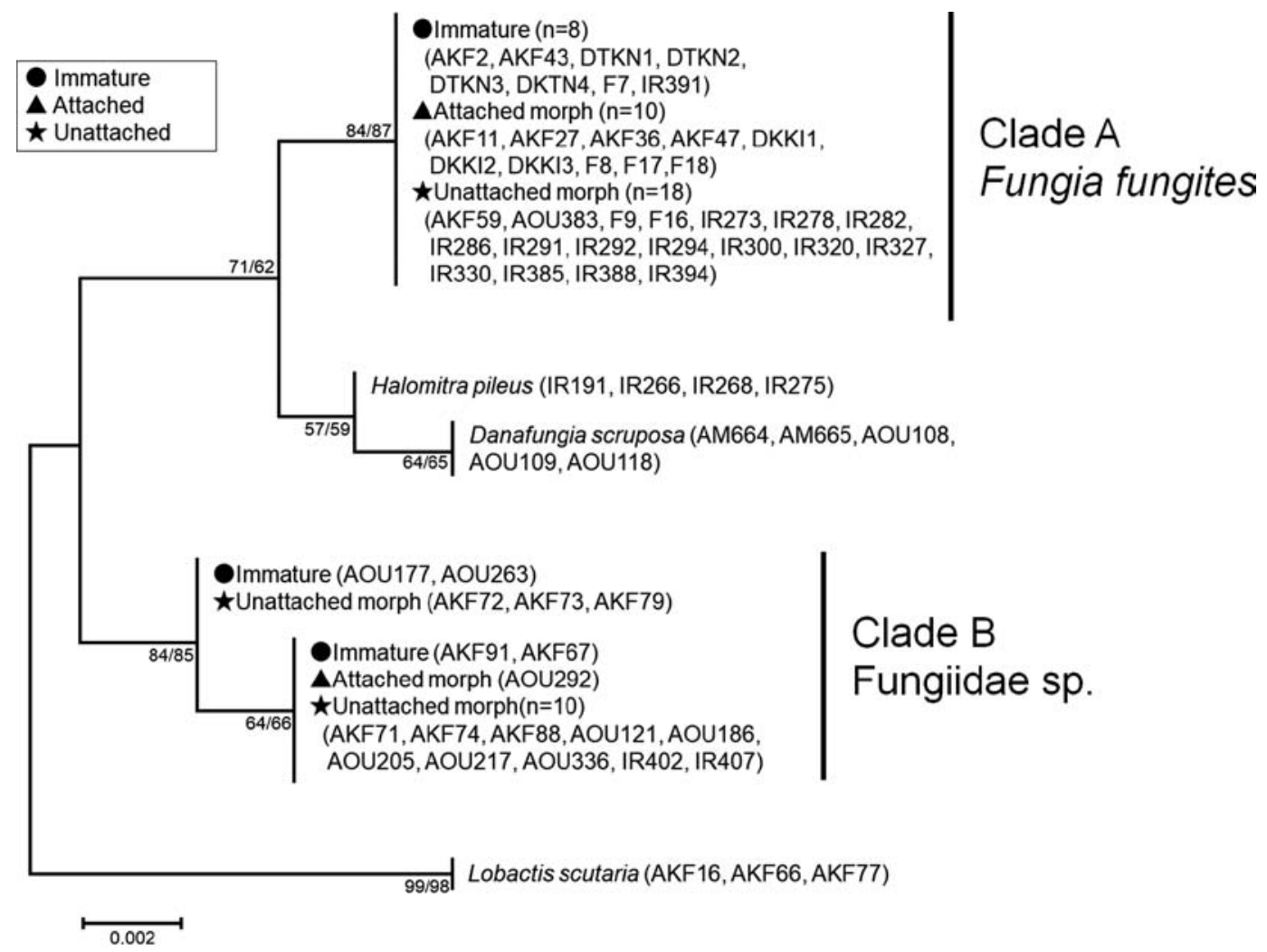

FIGURE 3 Maximum likelihood (ML) tree based on COI sequences. Numbers on main branches show percentages of bootstrap values $(>50 \%)$ in neighbor-joining $(\mathrm{NJ})$ and ML.

of costal spines $\left(3^{-16}\right.$ spines per $\mathrm{cm}$ in clade $\mathrm{A}$, and $5^{-24}$ spines per $\mathrm{cm}$ in clade B) was not significant $(U=285.5, N=54, P=0.4797)$. The second was the number of septa in relation to corallum diameter. The number of septa increased according to increasing corallum size in both clades (fig. 6), and was significantly higher in clade A (3.17-5.31) than clade B (2.85-4.54) (table 2, Mann-Whitney U test: $U=119, N=54, P=0.0002)$. The third was the shape of septal teeth. In clade A, these were regularly or irregularly angular in immature specimens and the attached morph, and regularly or irregularly lobate and angular in the unattached morph (fig. 7). In contrast, in clade B, there was fine septal dentation in immature specimens and the attached morph, and angular septal teeth in the unattached morph (fig. 8). Because of these differences between clades, septal teeth look coarser in clade A than in clade B.

To clarify the morphological differences in growth stages between and within clades, we performed pairwise comparisons for density of septal dentation, which was a major morphological difference between two clades, among the three groups (immature specimens, attached morphs, and unattached morphs). For the attached morph, the density of septal dentation in clade B (22-26 teeth per $\mathrm{cm}$ ) was higher than those in clade A (9-21 teeth per $\mathrm{cm})$, although we did not test statistically for the attached morph in clade B because there was only one sample. 


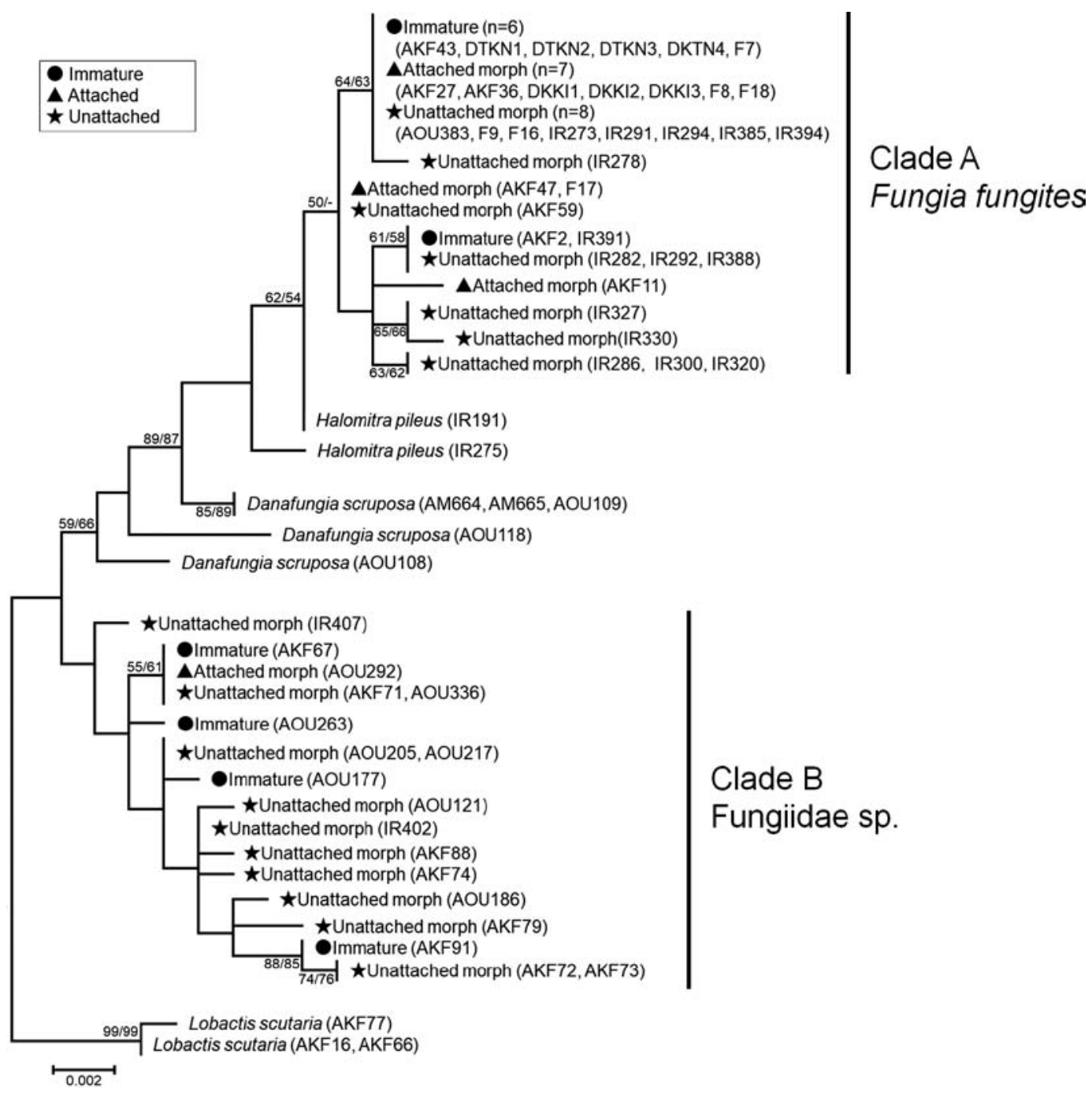

FIGURE 4 Maximum likelihood (ML) tree based on ITS sequences. Numbers on main branches show percentages of bootstrap values $(>50 \%)$ in neighbor-joining $(\mathrm{NJ})$ and $\mathrm{ML}$.

For other groups, the values were significantly different within the groups (Kruskal-Wallis test, $P<\mathbf{0 . 0 0 0 1 )}$. The unattached morph was significantly different between clades A and B (Steel-Dwass test, $P<0.01$ ), whereas immature specimens were not significantly different although the values look like different between clades (table 3).

For micromorphology, we could not find clear differences in the septal teeth and septal sides between clades A and B (fig. 9) because the morphology was too variable even within each clade.

\section{Discussion}

\section{Species complex}

We discovered a statistical difference in the density of septal dentation of specimens between the two clades of $F$. fungites regardless 


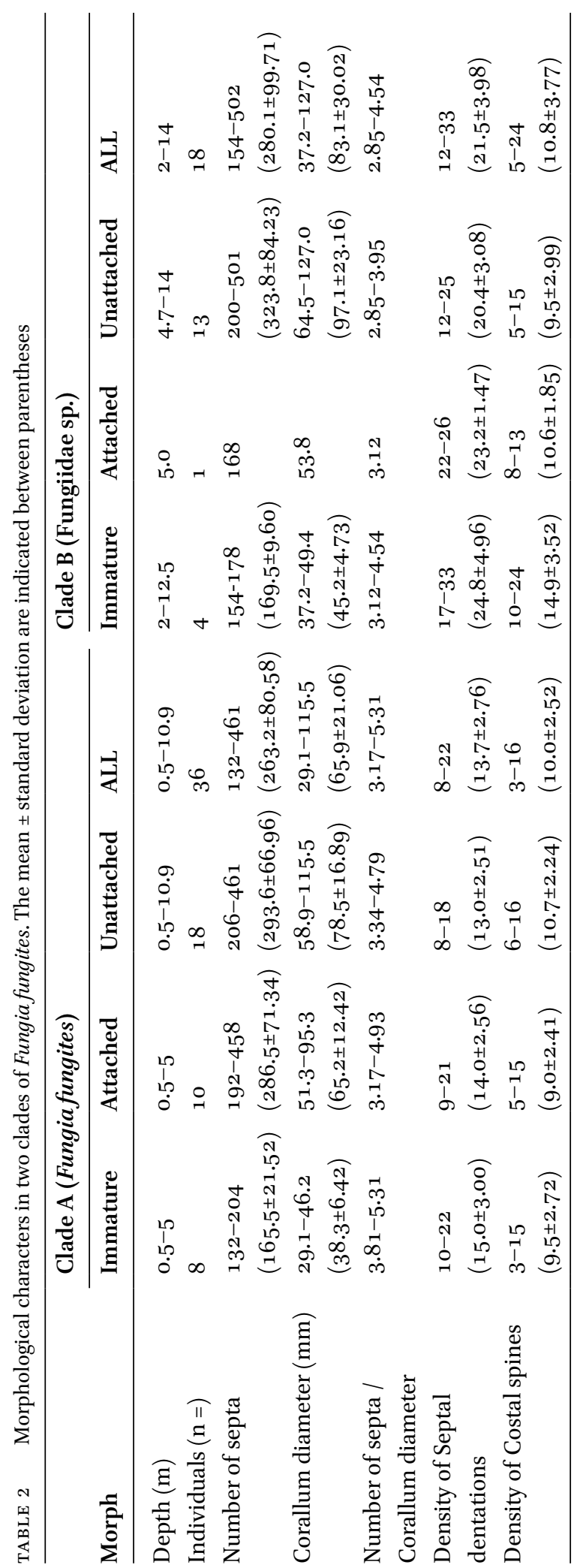




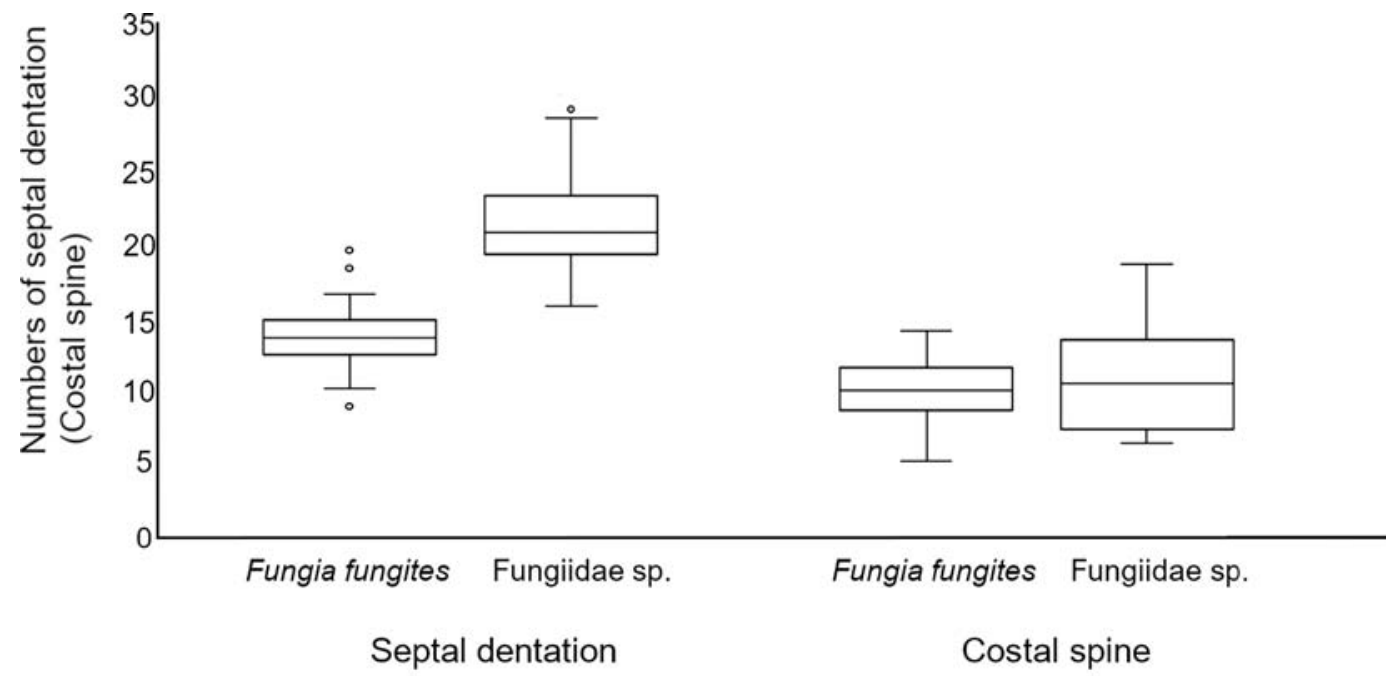

FIGURE 5 Box plot of density of septal dentation and costal spine between clades A (Fungia fungites) and $\mathrm{B}$ (Fungiidae sp.). The lower and upper limits of the rectangular boxes indicate the 25 to $75 \%$ range, and the horizontal line within the boxes is the median $(50 \%)$.

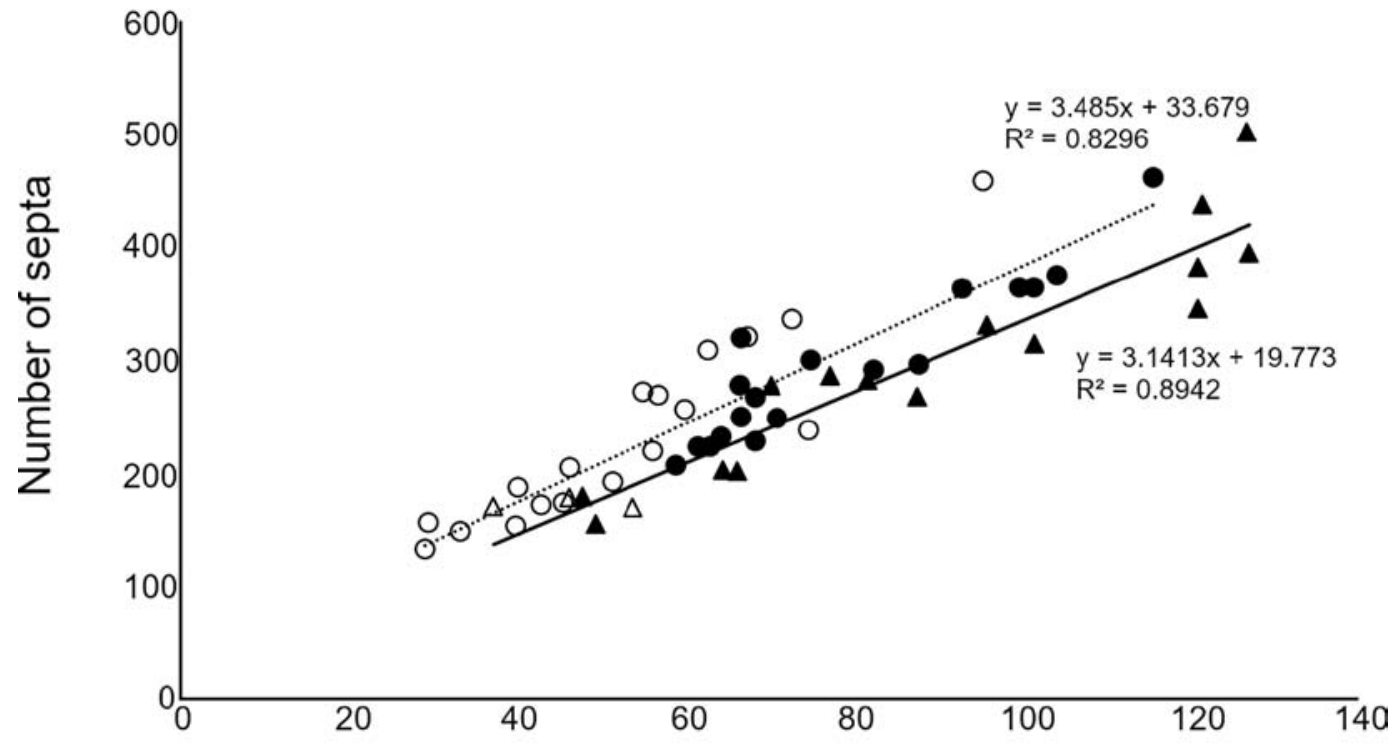

Corallum diameter $(\mathrm{mm})$

FIGURE 6 Scatter plot of numbers of septa versus corallum diameter between clades A (Fungia fungites) and B (Fungiidae sp.). Plots for F. fungites are shown by circle whereas Fungiidae sp. are shown by triangle. Blank plots mean attached specimens and plots for solid mean unattached specimens.

of morphs and growth stages. Moreover, they were also different in the number of septa per corallum and shape of septal teeth (fig. 6). These results revealed that $F$. fungites is a species complex that contained one other species. As shown in the photographs of the neotype, the type specimen of $F$. fungites has a density of septal dentations of seven 
TABLE 3 Pairwise comparison of density of septal dentation between immature type and two morphs

\begin{tabular}{|c|c|c|c|c|c|c|c|}
\hline & & \multicolumn{3}{|l|}{ Clade A } & \multicolumn{3}{|l|}{ Clade B } \\
\hline & & Immature & Attached & Unattached & Immature & Attached & Unattached \\
\hline \multirow[t]{3}{*}{ Clade A } & Immature & - & & & & & \\
\hline & Attached & 0.963 & - & & & & \\
\hline & Unattached & $0.65^{2}$ & 0.940 & - & & & \\
\hline \multirow[t]{3}{*}{ Clade B } & Immature & 0.0804 & $0.037^{*}$ & 0.184 & - & & \\
\hline & Attached & NA & NA & NA & NA & - & \\
\hline & Unattached & $0.00982^{* *}$ & $0.00113^{* *}$ & $<0.001 * *$ & 0.506 & NA & - \\
\hline
\end{tabular}

Abbreviations and symbols: NA, Not Analysis; ${ }^{*}, p<0.05 ;{ }^{* *}, p<0.01$.

to 12 teeth per $\mathrm{cm}$ (fig. 10). Hoeksema (1989) showed that the intraspecific range in $F$. fungites for density of septal dentation was 8-25, which is more similar to those of clade $A$ $(8-22)$ than to clade B (12-33). In addition, the septal teeth shape of the neotype is much more similar to that of specimens of clade $\mathrm{A}$ (fig. 7) than that of clade B (fig. 8). Thus, morphologically, specimens of clade A are identified as true $F$. fungites.

Our molecular phylogenetic analysis showed that outgroups D. scruposa and H. pileus were genetically more closely related to clade $\mathrm{A}$ than clade B. The morphological characteristics of $D$. scruposa and $H$. pileus are distinct from both clades A and B of $F$. fungites. For instance, $H$. pileus is largely different in colony shape (polystomatous and therefore with a much larger maximum corallum size: $>600$ mm) (Hoeksema, 1991) than clades A and B (monostomatous and smaller size: $<310 \mathrm{~mm}$ ) although the shape of costal spines of $\mathrm{H}$. pileus is similar. The septal teeth of $H$. pileus are also nearly similar, although more protruding around the mouths, but this cannot be said of its sister species, Halomitra clavator Hoeksema, 1989, which shows club-shaped septal teeth that are more or less uniform, also around the mouths (Hoeksema, 1989; Hoeksema \& Gittenberger, 2010). Danafungia scruposa differs from them by showing rudimentary (poorly developed) costal spines on their higher order costa. Furthermore, the shape of costal spines is also different $-D$. scruposa has spindlier spines whereas specimens in clades A and B have more triangular or club-like spines. In fact, the morphological differences between two genera Danafungia and Fungia consist predominantly of the shape and development of their costal spines.

Hence, based on molecular and morphological data, we conclude that specimens in clade $\mathrm{A}$ are true $F$. fungites, and that those in clade B are of a yet unidentified species belonging to a different genus than Fungia. So far, $F$. fungites contains over 30 junior synonyms (see Hoeksema, 1989; Hoeksema \& Cairns, 2019b). Therefore, to clarify whether this unidentified species, Fungiidae sp., has been described previously, we need to check all of the type specimens of those synonyms, which will be done in another paper with more detailed morphological comparisons.

The COI-ITS (supplementary fig. S1) tree showed that " $F$. fungites" (one sample from Indonesia) used in Gittenberger et al. (2011) was included in clade B. We also confirmed that the specimen had the typical morphological characteristics of Fungiidae sp. (clade B). Thus, this result suggests that Fungiidae sp. could be widely distributed in the western Pacific. 

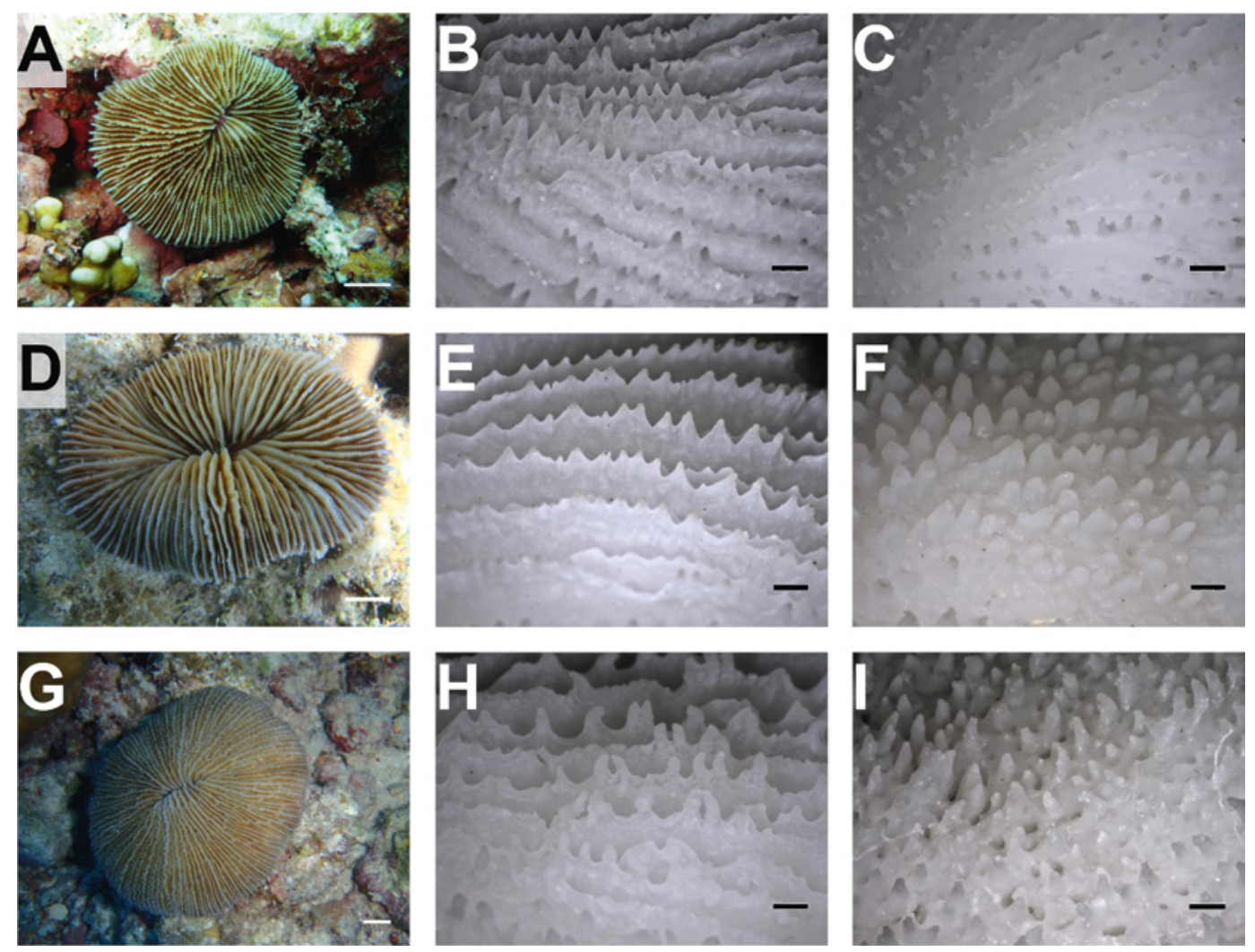

FIGURE 7 Specimens in Clade A (Fungia fungites). Scale bars: $1 \mathrm{~cm}$ for white bar, $1 \mathrm{~mm}$ for black bar. A. Living specimen of immature type (MUFS $\mathrm{C}_{307}$ ). B. Septal dentation (MUFS $\mathrm{C}_{307}$ ). C. Costal spine (MUFS $\mathrm{C}_{307}$ ). D. Living specimen of attached morph (MUFS C309). E. Septal dentation (MUFS C309). F. Costal spine (MUFS C309). G. Living specimen of unattached morph (MUFS C324). H. Septal dentation (MUFS $\mathrm{C}_{324}$ ). I. Costal spine (MUFS $\mathrm{C}_{324}$ ).

\section{Morphs}

Our molecular data showed that two morphs (attached and unattached morphs) were observed in both clades (i.e., two species), indicating that these two morphs represent intraspecific phenotypic differences. Although the two morphs result from intraspecific variation, the proportions of both morphs were different in each clade. The full-grown attached morph of clade B (Fungiidae sp.) was a single specimen with a diameter of $53.2 \mathrm{~mm}$, which is nearly immature in size (less than $5^{0} \mathrm{~mm}$ ). In contrast, for clade A (F. fungites), 10 specimens of the full-grown attached morph were included, in which four specimens were over $70 \mathrm{~mm}$ in diameter. Considering these results, the attached morph most commonly found in the field would be $F$. fungites.

"Fungia sp. (Sessile)" was the unidentified species reported for an attached morph in Nishihira \& Veron (1995). In verifying the morphological characteristics based on photographs of "F. sp. (Sessile)" shown in Nishihira \& Veron (1995), we identified it as the full-grown attached morph of clade A ( $F$. fungites). This identification is also supported by the fact that the shape of septal teeth is lobate and the septal face looks course, although the exact number of septa could not be counted 

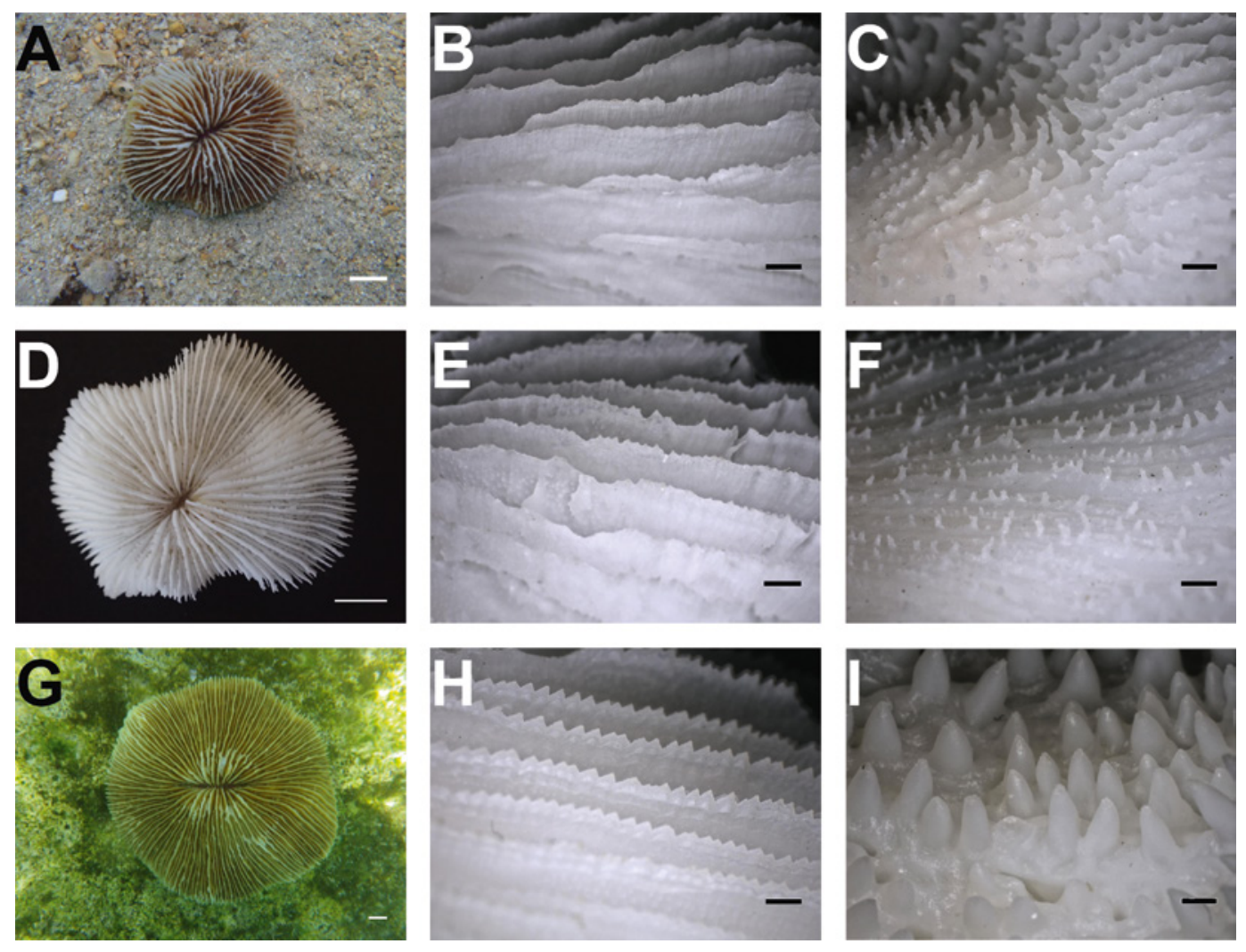

FIGURE 8 Specimens in Clade B (Fungiidae sp.). Scale bars: $1 \mathrm{~cm}$ for white bar, $1 \mathrm{~mm}$ for black bar. A. Living specimen of immature type (MUFS C335). B. Septal dentation (MUFS C335). C. Costal spine (MUFS C335). D. Corallites of attached morph (MUFS C188). E. Septal dentation (MUFS C188). F. Costal spine (MUFS C188). G. Living specimen of unattached morph (MUFS C338). H. Septal dentation (MUFS $\left.\mathrm{C}_{33} 8\right)$ I. Costal spine (MUFS C338).

from the photos. This is also consistent with the identification for the large, attached specimens with late detachment that were reported from the Gulf of Thailand (Hoeksema \& Yeemin, 2011).

\section{Ecologicalfeatures of two species}

In general, immature specimens of unattached morphs dissolve their stalk during growth in order to detach more easily from the substrate (Yamashiro \& Yamazato 1996; Hoeksema \& Yeemin 2011; Hoeksema \& Waheed, 2012). Therefore, the existence of the attached morph in both $F$. fungites and Fungiidae sp. could be caused by the delay of such a skeletal-dissolving mechanism. At this time, we do not know the mechanism but the attached morph looks like a neotenic characteristic because it retains the same form as the anthocaulus stage (= immature). The occurrence of the character states of attached vs. unattached in full grown mushroom corals used to be distinctive at genus level (Wells, 1966; Cairns, 1984; Hoeksema, 1989, 2009), but since the application of molecular methods this distinction has only remained at species level (Gittenberger et al., 2011; Benzoni et al., 2012). The present study shows that this distinction has also become less clear within a single species. 

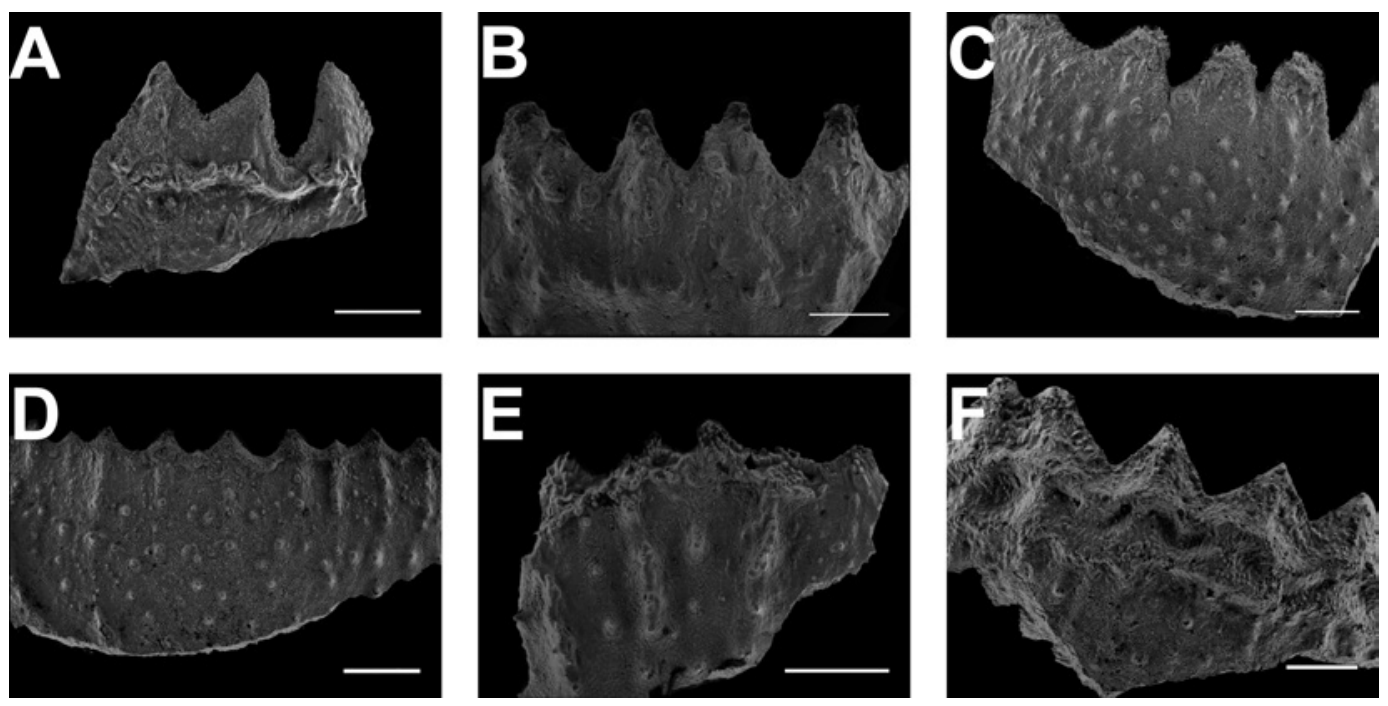

FIGURE 9 Micromorphology of septal side using scanning electron microscopy. Scale bars: $0.5 \mathrm{~cm}$. A. Immature type in Clade A (MUFS C307). B. Attached morph in Clade A (MUFS C309). C. Unattached morph in Clade A (MUFS C325). D. Immature type in Clade B (MUFS C166). E. Attached morph in Clade B (MUFS C188). C. Unattached morph in Clade B (MUFS C338).

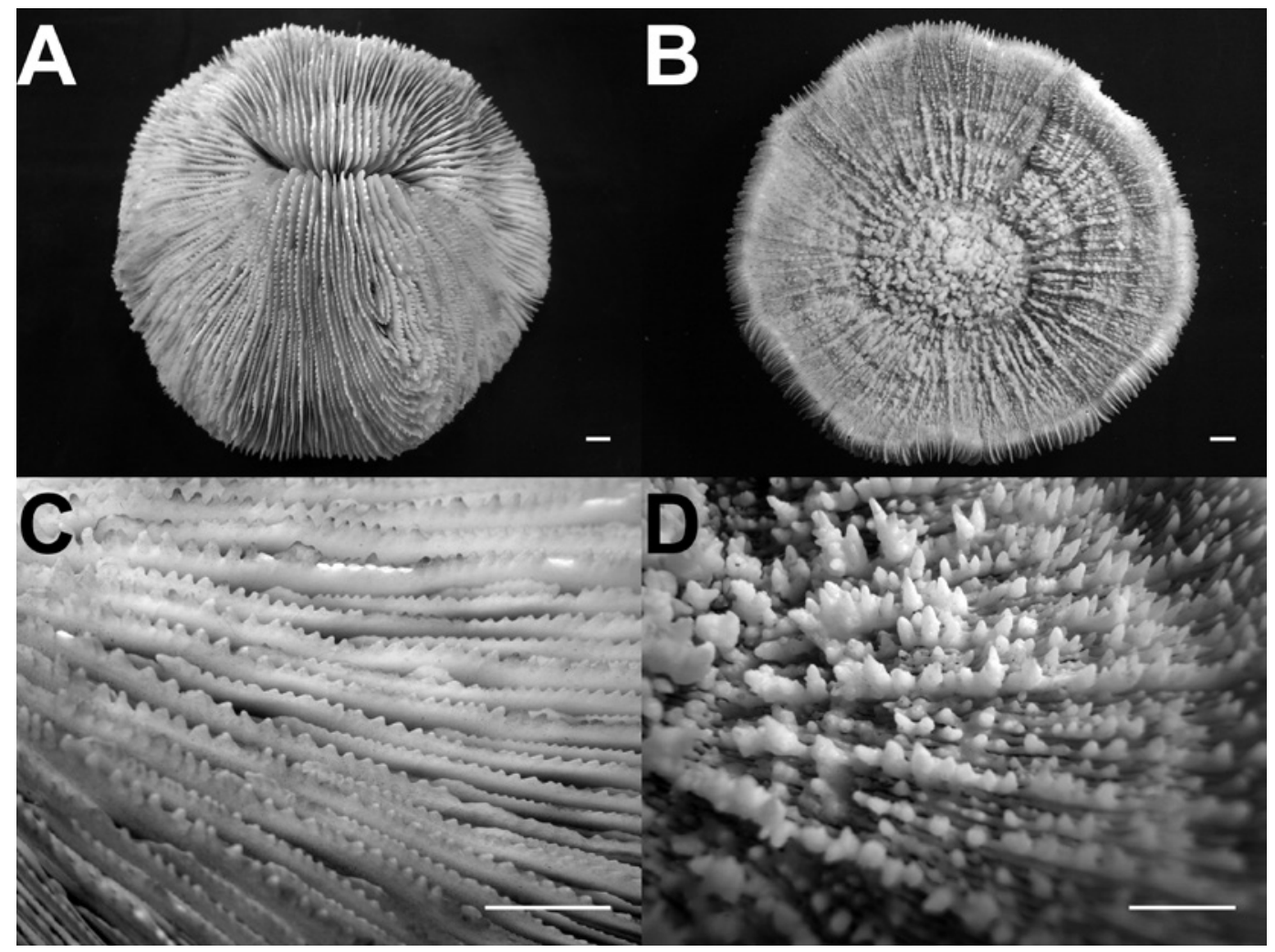

FIGURE 10 Neotype of Fungia fungites (RMNH16235). Scale bars: 1cm. A. Upper side. B. Basal side. C. Enlarged view of septa. D. Enlarged view of costal spines. 


\section{Conclusion}

The present study reveals that $F$. fungites has large phenotypic variation, including attached and unattached forms. This kind of intraspecific morphological variation has never been reported for mushroom corals but is not unique among scleractinian corals since the opposite pattern - an unattached form shown by an otherwise attached species - has been observed (Hoeksema, 2012; Hoeksema \& Wirtz, 2013). In mushroom corals, studies of intraspecific morphological variation with molecular data are limited (Hoeksema \& Moka, 1989; Hoeksema, 1993; Gittenberger \& Hoeksema, 2006), but are important for understanding the complexity of their morphology. We also found that $F$. fungites is a species complex including one more species (Fungiidae sp.) belonging to a different genus. We are now describing that taxon as a new genus and a new species.

We have also demonstrated the utility of molecular phylogenetic analysis using COI and ITS for the exploration of species complexes. Although new species of scleractinian corals have been discovered recently by more detailed phylogenetic analysis using four or more markers (Arrigoni et al., 2016a, b, 2019) or microsatellite loci (Warner et al., 2015), it would be possible to explore for species complexes at relatively low cost using only these two markers. We expect this simple method of analysis to emerge as the primary method used in the search for species complexes among scleractinian corals.

\section{Acknowledgements}

We thank Japanese Society for Coral Taxonomy for great assistance with sampling. This research was partially supported by a grant from Research Institute of Marine Invertebrates
Foundation, Japan for YO, and by Grant-inAid for Scientific Research (C) for HF. We are grateful to two anonymous reviewers for their constructive comments, which helped us to improve the manuscript.

\section{Supplementary material}

Supplementary material is available online at: https://doi.org/10.6o84/mg.figshare.10012436

\section{References}

Arrigoni, R., Terraneo, T.I., Galli, P. \& Benzoni, F. (2014a) Lobophylliidae (Cnidaria, Scleractinia) reshuffled: pervasive non-monophyly at genus level. Mol. Phylogenet. Evol., 73, 6o-64. doi:10.1016/j.ympev.2014.01.010

Arrigoni, R., Richards, Z.T., Chen, C.A., Baird, A.H. \& Benzoni, F. (2014b) Phylogenetic relationships and taxonomy of the coral genera Australomussa and Parascolymia (Scleractinia, Lobophylliidae). Contrib. Zool., 83, 195-215. doi:10.1163/18759866-08303004

Arrigoni, R., Kitano, Y.F., Stolarski, J., Hoeksema, B.W., Fukami, H., Stefani, F., Galli, P., Montano, S., Castoldi, E. \& Benzoni, F. (2014c) A phylogeny reconstruction of the Dendrophylliidae (Cnidaria, Scleractinia) based on molecular and micromorphological criteria, and its ecological implications. Zool. Scr., 43, 661-688. doi:10.1111/ zsc. 12072

Arrigoni, R., Berumen, M.L., Terraneo, T.I., Caragnano, A., Bouwmeester, J. \& Benzoni, F. (2015) Forgotten in the taxonomic literature: resurrection of the scleractinian coral genus Sclerophyllia (Scleractinia, Lobophylliidae) from the Arabian Peninsula and its phylogenetic relationships. Syst. Biodivers., 13, 140-163. doi:10.1080/ 14772000.2014.978915

Arrigoni, R., Benzoni, F., Huang, D., Fukami, H., Chen, C.A., Berumen, M.L., Hoogenboom, M., 
Thomson, D.P., Hoeksema, B.W., Budd, A.F., Zayasu, Y., Terraneo, T.I., Kitano, Y.F. \& Baird, A.H. (2016a) When forms meet genes: revision of the scleractinian genera Micromussa and Homophyllia (Lobophylliidae) with a description of two new species and one new genus. Contrib. Zool., 85, 387-422. doi:10.1163/18759866-08504002

Arrigoni, R., Berumen, M.L., Chen, C.A., Terraneo, T.I., Baird, A.H., Payri, C. \& Benzoni, F. (2016b) Species delimitation in the reef coral genera Echinophyllia and Oxypora (Scleractinia, Lobophylliidae) with a description of two new species. Mol. Phylogenet. Evol., 105, 146-159. doi:10.1016/j.ympev.2016.08.023

Arrigoni, R., Berumen, M.L., Huang, D., Terraneo, T.I. \& Benzoni, F. (2017) Cyphastrea (Cnidaria:Scleractinia: Merulinidae) in the Red Sea: phylogeny and a new reef coral species. Invertebr. Syst., 31, 141-156. doi:10.1071/IS16035

Arrigoni, R., Berumen, M.L., Stolarski, J., Terraneo, T.I. \& Benzoni, F. (2019) Uncovering hidden coral diversity: a new cryptic lobophylliid scleractinian from the Indian Ocean. Cladistics, 35, 301-328. doi:10.1111/cla.12346

Babcock, R.C., Baird, A.H., Piromvaragorn, S., Thomson, D.P. \& Willis, B.L. (2003) Identification of scleractinian coral recruits from IndoPacific Reefs. Zool. Stud., 42, 211-226. http:// www.sinica.edu.tw/zool/zoolstud/42.1/211.pdf

Baird, A.H. \& Babcock, R.C. (2000) Morphological differences among three species of newly settled pocilloporid coral recruits. Coral Reefs, 19, 179-183. doi:10.1007/PLoooo6955

Baird, A.H., Hoogenboom, M.O. \& Huang, D. (2017) Cyphastrea salae, a new species of hard coral from Lord Howe Island, Australia (Scleractinia, Merulinidae). ZooKeys, 662, 49-66. doi:10.3897/ zookeys.662.11454

Benzoni, F., Stefani, F., Pichon, M. \& Galli, P. (2010) The name game: morpho-molecular species boundaries in the genus Psammocora (Cnidaria, Scleractinia). Zool. J. Linn. Soc., 160, 421-456. doi:10.1111/j.1096-3642.2010.00622.x

Benzoni, F., Arrigoni, R., Stefani, F., Reijnen, B.T., Montano, S. \& Hoeksema, B.W. (2012)
Phylogenetic position and taxonomy of $C y$ closeris explanulata and C. wellsi (Scleractinia: Fungiidae): lost mushroom corals find their way home. Contrib. Zool., 81, 125-146. doi:10.1163/ 18759866-08103001

Benzoni, F., Arrigoni, R., Waheed, Z., Stefani, F. \& Hoeksema, B.W. (2014) Phylogenetic relationships and revision of the genus Blastomussa (Cnidaria: Anthozoa: Scleractinia) with description of a new species. Raffles Bull. Zool., 62, 358-378. https://lkcnhm.nus.edu.sg/app/ uploads/2017/06/62rbz358-378.pdf

Benzoni, F., Arrigoni, R., Berumen, M.L., Taviani, M., Bongaerts, P. \& Frade, P.R. (2018) Morphological and genetic divergence between Mediterranean and Caribbean populations of Madracis pharensis (Heller 1868) (Scleractinia, Pocilloporidae): too much for one species? Zootaxa, 4471, 473-492. doi:10.11646/zootaxa.4471.3.3

Bongaerts, P., Riginos, C., Ridgway, T., Sampayo, E.M., van Oppen, M.J., Englebert, N., Vermeulen, F. \& Hoegh-Guldberg, O. (2010) Genetic divergence across habitats in the widespread coral Seriatopora hystrix and its associated Symbiodinium. PLoS ONE, 5, e10871. doi:10.1371/journal. pone.0010871

Budd, A.F., Fukami, H., Smith, N.D. \& Knowlton, N. (2012) Taxonomic classification of the reef coral family Mussidae (Cnidaria: Anthozoa: Scleractinia). Zool. J. Linn. Soc., 166, 465-529. doi:10.1111/j.1096-3642.2012.00855.x

Budd, A.F., Woodell, J.D., Huang, D. \& Klaus, J.S. (2019) Evolution of the Caribbean subfamily Mussinae (Anthozoa: Scleractinia: Faviidae): transitions between solitary and colonial forms. J. Syst. Palaeontol., 17, 1361-1396. doi:10.1080/1477 2019.2018.1541932

Cairns, S.D. (1984) An application of phylogenetic analysis to the Scleractinia: Family Fungiidae. Palaeontogr. Am., 54, 49-57. https://repository. si.edu/handle/10088/7211

Carlon, D.B. \& Budd, A.F. (2002) Incipient speciation across a depth gradient in a scleractinian coral? Evolution, 56, 2227-2242. doi: 10.1111/j.0014-3820.2002.tboo147.x 
Chen, K.S., Hsieh, H.J., Keshavmurthy, S., Leung, J.K.L., Lien, I.T., Nakano, Y., Plathong, S., Huang, H. \& Chen, C.A. (2011) Latitudinal gradient of morphological variations in zebra coral Oulastrea crispata (Scleractinia: Faviidae) in the West Pacific. Zool. Stud., 50, 43-52. http://zoolstud. sinica.edu.tw/Journals/50.1/43.pdf

Fukami, H., Budd, A.F., Paulay, G., Sole-Cava, A., Chen, C.A., Iwao, K. \& Knowlton, N. (2004) Conventional taxonomy obscures deep divergence between Pacific and Atlantic corals. Nature, 427, 832-835. doi:10.1038/nature02339

Fukami, H., Chen, C.A., Budd, A.F., Collins, A., Wallace, C., Chuang, Y.Y., Chen, C., Dai, C.F., Iwao, K., Sheppard, C. \& Knowlton, N. (2008) Mitochondrial and nuclear genes suggest that stony corals are monophyletic but most families of stony corals are not (Order Scleractinia, Class Anthozoa, Phylum Cnidaria). PLoS ONE, 3, e3222. doi:10.1371/journal.pone.0003222

Gilmour, J.P. (2004) Size-structures of populations of the mushroom coral Fungia fungites: the role of disturbance. Coral Reefs, 23, 493-504. doi:10.1007/soo338-004-0427-5

Gittenberger, A. \& Hoeksema, B.W. (2006) Phenotypic plasticity revealed by molecular studies on reef corals of Fungia (Cycloseris) spp. (Scleractinia:Fungiidae) near river outlets. Contrib.Zool., 75, 195-201. doi:10.1163/18759866-0750304008

Gittenberger, A., Reijnen, B.T. \& Hoeksema, B.W. (2011) A molecularly based phylogeny reconstruction of mushroom corals (Scleractinia: Fungiidae) with taxonomic consequences and evolutionary implications for life history traits. Contrib. Zool., 80, 107-132. doi:10.1163/18759866-08002002

Goffredo, S. \& Chadwick-Furman, N.E. (2003) Comparative demography of mushroom corals (Scleractinia: Fungiidae) at Eilat, northern Red Sea. Mar. Biol., 142, 411-418. doi:10.1007/ soo227-002-0980-9

Hoeksema, B.W. (1989) Taxonomy, phylogeny and biogeography of mushroom corals (Scleractinia: Fungiidae). Zool. Verh., 254, 1-295. https:// www.repository.naturalis.nl/record/317727
Hoeksema, B.W. (1991) Evolution of body size in mushroom corals (Scleractinia: Fungiidae) and its ecomorphological consequences. Neth. J. Zool., 41, 122-139. doi:10.1163/156854291X00072

Hoeksema, B.W. (1993) Phenotypic corallum variability in Recent mobile reef corals. Cour. Forsch. Senck. 164, 263-272.

Hoeksema, B.W. (2009) Attached mushroom corals (Scleractinia: Fungiidae) in sediment-stressed reef conditions at Singapore, including a new species and a new record. Raffles Bull. Zool., Supplement 22, 81-90. https://lkcnhm.nus .edu.sg/app/uploads/2017/06/s22rbzo81-09o .pdf

Hoeksema, B.W. (2012) Extreme morphological plasticity enables a free mode of life in Favia gravida at Ascension Island (South Atlantic). Mar. Biodivers., 42, 289-295. doi:10.1007/ s12526-011-0106-Z

Hoeksema, B.W. (2014) The "Fungia patella group" (Scleractinia, Fungiidae) revisited with a description of the mini mushroom coral Cycloseris boschmai sp. n. Zookeys, 371, 57-84. doi:10.3897/ zookeys.371.6677

Hoeksema, B.W. \& Benzoni, F. (2013) Multispecies aggregations of mushroom corals in the Gambier Islands, French Polynesia. Coral Reefs, 32, 1041. doi:10.1007/soo338-013-1054-9

Hoeksema, B.W. \& Cairns, S. (2019a) World List of Scleractinia. Scleractinia incertae sedis. Accessed 4 July 2019: World Register of Marine Species at: http://www.marinespecies.org/aphia.php?p=taxdetails\&id=266986

Hoeksema, B.W. \& Cairns, S. (2019b) World List of Scleractinia. Fungia fungites (Linnaeus, 1758). Accessed 4 July 2019: World Register of Marine Species at: http://www.marinespecies.org/aphia.php? $=$ =taxdetails\&id $=20735^{\circ}$

Hoeksema, B.W. \& Gittenberger, A. (2010) High densities of mushroom coral fragments at West Halmahera, Indonesia. Coral Reefs, 29, 691. doi:10.1007/s00338-010-0616-3

Hoeksema, B.W. \& Moka, W. (1989) Species assemblages and phenotypes of mushroom corals (Fungiidae) related to coral reef habitats Downloaded from Brill.com04/26/2023 11:58:21AM 
in the Flores Sea. Neth. J. Sea Res., 23, 149-160. doi:10.1016/oo77-7579(89)90oo9-4

Hoeksema, B.W. \& Waheed, Z. (2012) Onset of autotomy in an attached Cycloseris coral. $\mathrm{Ga}$ laxea J. Coral Reef Stud., 14, 1-2. doi:10.3755/ galaxea.14.25

Hoeksema, B.W. \& Wirtz, P. (2013) Over 130 years of survival by a small, isolated population of Favia gravida corals at Ascension Island (South Atlantic). Coral Reefs, 32, 551. doi:10.1007/ s00338-012-1002-0

Hoeksema, B.W. \& Yeemin, T. (2011) Late detachment conceals serial budding by the freeliving coral Fungia fungites in the Inner Gulf of Thailand. Coral Reefs, 30, 975. doi:10.1007/ soo338-011-0784-9

Huang, D., Meier, R., Todd, P.A. \& Chou, L.M. (2008) Slow mitochondrial COI sequence evolution at the base of the metazoan tree and its implications for DNA barcoding. J. Mol. Evol., 66, 167174. doi:10.1007/soo239-0o8-9069-5

Huang, D., Benzoni, F., Fukami, H., Knowlton, N., Smith, N.D. \& Budd, A.F. (2014a) Taxonomic classification of the reef coral families Merulinidae, Montastraeidae, and Diploastraeidae (Cnidaria: Anthozoa: Scleractinia). Zool. J. Linn. Soc., 171, 277-355. doi:10.1111/zoj.12140

Huang, D., Benzoni, F., Arrigoni, R., Baird, A.H., Berumen, M.L., Bouwmeester, J., Chou, L.M., Fukami, H., Licuanan, W.Y., Lovell, E.R. \& Meier, R. (2014b) Towards a phylogenetic classification of reef corals: the Indo-Pacific genera Merulina, Goniastrea and Scapophyllia (Scleractinia, Merulinidae). Zool. Scr., 43, 531-548. doi:10.1111/ zsc.12061

Huang, D., Arrigoni, R., Benzoni, F., Fukami, H., Knowlton, N., Smith, N.D., Stolarski, J., Chou, L.M. \& Budd, A.F. (2016) Taxonomic classification of the reef coral family Lobophylliidae (Cnidaria: Anthozoa: Scleractinia). Zool. J. Linn. Soc., 178, 436-481. doi:10.1111/zoj.12391

Keshavmurthy, S., Yang, S.Y., Alamaru, A., Chuang, Y.Y., Pichon, M., Obura, D., Fontana, S., De Palmas, S., Stefani, F., Benzoni, F., MacDonald, A., Noreen, A.M.E., Chen, C., Wallace,
C.C., Pillay, R.M., Denis, V., Amri, A.Y., Reimer, J.D., Mezaki, T., Sheppard, C., Loya, Y., Abelson, A., Mohammed, M.S., Baker, A.C., Mostafavi, P.G., Suharsono, B.A. \& Chen, C.A. (2013) DNA barcoding reveals the coral "laboratoryrat", Stylophora pistillata encompasses multiple identities. Sci. Rep., 3, 1520. doi:10.1038/ srepo1520

Kitahara, M.V., Fukami, H., Benzoni, F. \& Huang, D. (2016) The new systematics of Scleractinia: integrating molecular and morphological evidence. In: S. Goffredo, Z. Dubinsky (Eds) The Cnidaria, Past Present and Future, pp. 41-59. Springer, Cham, Switzerland. doi:10.1007/978-3-319-31305-4_4

Kitano, Y.F., Benzoni, F., Arrigoni, R., Shirayama, Y., Wallace, C.C. \& Fukami, H. (2014) A phylogeny of the family Poritidae (Cnidaria, Scleractinia) based on molecular and morphological analyses. PLoS ONE, 9, e98406. doi:10.1371/journal. pone.0098406

Klunzinger, C.B. (1879) Die Korallenthiere des Rothen Meeres, III. Theil: Die Steinkorallen. Zweiter Abschnitt: Die Asteraeaceen und Fungiaceen. Gutmann, Berlin.

Kumar, S., Stecher, G. \& Tamura, K. (2016) MEGA7: molecular evolutionary genetics analysis version 7.0 for bigger datasets. Mol. Biol. Evol., 33, 1870-1874. doi:10.1093/molbev/mswo54

Ladner, J.T. \& Palumbi, S.R. (2012) Extensive sympatry, cryptic diversity and introgression throughout the geographic distribution of two coral species complexes. Mol. Ecol., 21, 22242238. doi:10.1111/j.1365-294X.2012.05528.x

Lamarck, J.B. (1801) Systême des animaux sans vertèbres; ou, Tableau général des classes, des classes, des orres et des genres de ces animaux. Deterville, Paris. doi:10.5962/bhl.title.14255

Linnaeus, C. (1758) Systema Naturae per regna tria naturae, secundum Classes, Ordines, Genera, Species, cum characteribus, differentiis, sonymis, locis. Laurentius Salvius, Holmiae. doi:10.5962/ bhl.title.542

Luzon, K.S., Lin, M.F., Ablan-Lagman, M.C., Licuanan, W.Y. \& Chen, C.A. (2017) Resurrecting Downloaded from Brill.com04/26/2023 11:58:21AM via free access 
a subgenus to genus: molecular phylogeny of Euphyllia and Fimbriaphyllia (order Scleractinia; family Euphyllidae; clade V). PeerJ, 5, e4074. doi:10.7717/peerj.4074

Nakabayashi, A., Yamakita, T., Nakamura, T., Aizawa, H., Kitano, Y.F., Iguchi, A., Yamano, H., Nagai, S., Agostini, S., Teshima, K.M. \& Yasuda, N. (2019) The potential role of temperate Japanese regions as refugia for the coral Acropora hyacinthus in the face of climate change. Sci. Rep., 9, 1892. doi:10.1038/s41598-01838333-5

Nishihira, M. \& Veron, J.E.N. (1995) Hermatypic Corals of Japan. Kaiyusha, Tokyo. (in Japanese) Oku, Y., Naruse, T. \& Fukami, H. (2017) Morphomolecular evidence for polymorphism in the mushroom coral Cycloseris hexagonalis (Scleractinia: Fungiidae), with a new phylogenetic position and the establishment of a new genus for this species. Zool. Sci., 34, 242-251. doi:10.2108/zs160o65

R Core Team. (2019) R: A language and environment for statistical computing. R Foundation for Statistical Computing, Vienna, Austria. https://www.R-project.org/.

Richards, Z.T., Berry, O. \& van Oppen, M.J.H. (2016) Cryptic genetic divergence within threatened species of Acropora coral from the Indian and Pacific Oceans. Conserv. Genet., 17, 577-591. doi:10.1007/s10592-015-0807-o

Richards, Z.T., Carvajal, J.I., Wallace, C.C., \& Wilson, N.G. (2019) Phylotranscriptomics confirms Alveopora is sister to Montipora within the family Acroporidae. Mar. Genomics. doi:10.1016/j. margen.2019.100703

Schmidt-Roach, S., Lundgren, P., Miller, K.J., Gerlach, G., Noreen, A.M.E. \& Andreakis, N. (2013) Assessing hidden species diversity in the coral Pocillopora damicornis from Eastern Australia. Coral Reefs, 32, 161-172. doi:10.1007/ soo338-012-0959-Z

Stefani, F., Benzoni, F., Yang, S.Y., Pichon, M., Galli, P. \& Chen, C.A. (2011) Comparison of morphological and genetic analyses reveals cryptic divergence and morphological plasticity in
Stylophora (Cnidaria, Scleractinia). Coral Reefs, 30, 1033-1049. doi:10.1007/soo338-011-0797-4

Suzuki, G., Keshavmurthy, S., Hayashibara, T., Wallace, C.C., Shirayama, Y., Chen, C.A. \& Fukami, H. (2016) Genetic evidence of peripheral isolation and low diversity in marginal populations of the Acropora hyacinthus complex. CoralReefs, 35,1419-1432. doi:10.1007/soo338-0161484-2

Terraneo, T.I., Berumen, M.L., Arrigoni, R., Waheed, Z., Bouwmeester, J., Caragnano, A., Stefani, F. \& Benzoni, F. (2014) Pachyseris inattesa sp. n. (Cnidaria, Anthozoa, Scleractinia): a new reef coral species from the Red Sea and its phylogenetic relationships. ZooKeys, 433, 1-30. doi:10.3897/ zookeys.433.8036

Todd, P.A. (2008) Morphological plasticity in scleractinian corals. Biol. Rev., 83, 315-337. doi: 10.1111/j.1469-185X.2008.00045.X

Wallace, C.C., Chen, C.A., Fukami, H. \& Muir, P.R. (2007) Recognition of separate genera within Acropora based on new morphological, reproductive and genetic evidence from Acropora togianensis, and elevation of the subgenus Isopora Studer, 1878 to genus (Scleractinia: Astrocoeniidae; Acroporidae). Coral Reefs, 26, 231239. doi:10.1007/soo338-007-0203-4

Warner, P.A., van Oppen, M.J. \& Willis, B.L. (2015) Unexpected cryptic species diversity in the widespread coral Seriatopora hystrix masks spatial-genetic patterns of connectivity. Mol. Ecol., 24, 2993-3008. doi:10.1111/mec.13225

Wei, N.V., Wallace, C.C., Dai, C.F., Pillay, K.R.M. \& Chen, C.A. (2006) Analyses of the ribosomal internal transcribed spacers (ITS) and the $5.8 \mathrm{~S}$ gene indicate that extremely high rDNA heterogeneity is a unique feature in the scleractinian coral genus Acropora (Scleractinia; Acroporidae). Zool. Stud., 45, 404-418. http://zoolstud. sinica.edu.tw/Journals/45·3/404.pdf

Wells, J.W. (1966) Evolutionary development in the scleractinian family Fungiidae. In: W.J. Rees (Ed) The Cnidaria and their Evolution, Symposia of the Zoological Society London 16, pp. 223-246, pl. 1. Academic Press, London. 
Yamashiro, H. \& Yamazato, K. (1996) Morphological studies of the soft tissues involved in skeletal dissolution in the coral Fungia fungites. Coral Reefs, 15, 177-180. doi:10.1007/BFo1145889
RECEIVED: 8 JULY 2019 | REVISED AND ACCEPTED: 17 OCTOBER 2019

EDITOR: D.W. HUANG 